\title{
The Membrane-bound Cytochromes of an Aerobically Grown, Extremely Thermophilic Bacterium, PS3: Characterization by Spectral Deconvolution Coupled with Potentiometric Analysis
}

\author{
By R. K. POOLE, ${ }^{1 *}$ J. E. VAN WIELINK, ${ }^{2}$ B. S. BAINES,${ }^{1}$ \\ W. N. M. REIJNDERS, ${ }^{2}$ I. SALMON ${ }^{1} \uparrow$ AND L. F. OLTMANN ${ }^{2}$ \\ ${ }^{1}$ Department of Microbiology, Queen Elizabeth College, University of London, Campden Hill, \\ London W8 $7 A H$, U.K. \\ ${ }^{2}$ Department of Microbiology, Biological Laboratory, Vrije Universiteit, De Boelelaan 1087, \\ 1007 MC Amsterdam, The Netherlands
}

(Received 15 October 1982; revised 20 December 1982)

\begin{abstract}
Cytochromes of the $a, b$ and $c$ types in membranes from the thermophilic bacterium PS3 have been characterized with respect to their spectral, potentiometric and ligand-binding properties. The integrated approach used (a) conventional potentiometric analysis with non-linear leastsquare analysis, (b) incorporation of the potentiometric procedures into a spectral decomposition protocol at 298 and $77 \mathrm{~K}$, (c) fourth-order finite difference and fourth derivative analysis, and (d) photodissociation studies of the CO-liganded components. Either one $c$-type cytochrome with a split $\alpha$-band $(547,552 \mathrm{~nm}$ at $77 \mathrm{~K}$ ) or two cytochromes $c$ with similar redox potentials (approx. $+230 \mathrm{mV}$ ) were found, together with at least three $b$-type cytochromes $(554,557$ and $561 \mathrm{~nm}$ at $77 \mathrm{~K})$. On the basis of its high redox potential $(+104 \mathrm{mV})$, cytochrome $b_{557}$ was tentatively equated with the $o$-type oxidase of this organism. A $c$-type cytochrome that formed a photodissociable complex with $\mathrm{CO}$ was also detected. The $\alpha$-band of the previously purified cytochrome $c$ oxidase was resolved into two components, having spectral and potentiometric properties remarkably similar to those of the analogous mitochondrial oxidase.
\end{abstract}

\section{INTRODUCTION}

Interest in bacterial respiratory systems has been heightened in recent years by the finding that certain cytochrome oxidases of the $a a_{3}$-type bear a remarkable resemblance to the cytochrome $c$ oxidase (EC 1.9.3.1) of eukaryotic mitochondria, but appear to have much simpler subunit compositions (for a review, see Ludwig, 1980). The best-characterized example is perhaps Paracoccus denitrificans, long regarded as a 'mitochondrion-like' bacterium although, under appropriate growth conditions, its respiratory chain also contains the alternative cytochrome oxidases $o$ (Sapshead \& Wimpenny, 1972) and $d$ (Henry \& Vignais, 1979) with no obvious mitochondrial counterparts.

From the thermophilic bacterium, PS3 (not firmly identified but believed to be Bacillus stearothermophilus; T. Oshima, personal communication), Sone et al. (1979) purified a cytochrome oxidase that was claimed to have only one type of polypeptide subunit. The enzyme contained haems $a$ and $a_{3}$, cytochrome $c$ and intrinsic copper. Later experiments, however (E. Yang \& N. Sone, unpublished; cited by Ludwig, 1980), suggested that an $a_{3}$ component was missing and that the oxidase comprised cytochromes $a, o$ and $c$ in molar ratios $5: 1: 5$, a novel configuration. This failure to find cytochrome $a_{3}$ may have resulted from poorly defined growth

† Present address: Biological Laboratory, The University, Canterbury, Kent CT2 7NJ, U.K.

Abbreviation: TMPD, $N, N, N^{\prime}, N^{\prime}$-tetramethyl-p-phenylenediamine. 
conditions, since in membranes from adequately aerated cultures, Poole (1981) clearly demonstrated the presence of a CO-binding $a$-type cytochrome with absorption maxima at 602 to $605 \mathrm{~nm}$ (thus, by definition, $a_{3}$ ), cytochrome $o$ and a cytochrome $c$ that also bound $\mathrm{CO}$ and NO. The inability of Fee et al. (1978) to observe any perturbation by $\mathrm{CO}$ of the optical spectra of PS3 membranes is unexplained. Most recently, Sone \& Yanagita (1982) have described a revised purification of the oxidase from vigorously aerated cells and confirmed that it is an $a a_{3}$ type, but with three subunit types.

There is particular interest in the thermophile PS3, since (1) the purified oxidase reconstituted into liposomes gave the first indication that a terminal bacterial oxidase could act as a proton translocator (Sone et al., 1979), and (2) this oxidase and other energy-transducing proteins so far isolated exhibit remarkable thermostability (e.g. Sone et al., 1979; Goto et al., 1980).

Apart from the existence of $c, o$ (i.e. $b$ ) and $a a_{3}$ types of cytochromes (cytochromes $o$ and $a a_{3}$ being oxidases; Poole $e t$ al., 1982) and a preliminary characterization of the purified $a a_{3}$ oxidase complex, nothing is known about the composition of the respiratory chain of this thermophile.

The aim of the present work was to characterize as fully as possible the membrane-bound cytochromes of PS3 grown under one set of carefully controlled conditions and to assess how similar this respiratory chain is to that of mitochondria. This paper illustrates the use of an integrated approach to the spectral, potentiometric and ligand-binding properties of these cytochromes.

\section{METHODS}

Organism, growth conditions and preparation of membranes. The organism was generously donated by $\mathrm{Dr} \mathrm{T}$. Oshima (Mitsubishi-Kasei Institute of Life Sciences, Machida-Shi, Tokyo, Japan). The procedures described previously (Poole, 1981) for maintenance and growth were followed, except that in some cases cultures (10 litres) were grown in a 12 litre Biostat-V fermenter (FT Scientific Instruments, Bredon, Glos. GL20 7HH, U.K.). The temperature was $65^{\circ} \mathrm{C}$, and the stirring speed 500 r.p.m.; sterile air was sparged into the medium at $0.51 \mathrm{~min}^{-1}$ $(1 \text { medium })^{-1}$. The final cell yield (approx. $1.8 \mathrm{~g}$ wet $\mathrm{wt}^{-1}$ ) and mean generation time (approx. $20 \mathrm{~min}$ ) were similar to those obtained in a smaller vessel (Poole, 1981).

Cultures were harvested by continuous-flow centrifugation with either an MSE continuous action rotor in an MSE 18 centrifuge or with an Alfa-Laval separator. Cells pelleted from the resulting slurry by centrifugation at $12000 \mathrm{~g}\left(r_{\mathrm{av}}\right)$ for $5 \mathrm{~min}$ were washed once under the same conditions with $50 \mathrm{~mm}-\mathrm{Tris} / \mathrm{H}_{2} \mathrm{SO}_{4}(\mathrm{pH} 8 \cdot 0)$. Washed membranes were prepared from lysozyme-digested cells as described by Yoshida et al. (1975) except that the enzyme concentration was increased from 1 to $2 \mathrm{mg}$ (g wet wt cells) ${ }^{-1}$. Pelleted membranes were stored below $-20^{\circ} \mathrm{C}$ until used. Protein content of membrane suspensions was assayed by the biuret method (Herbert et al., 1971) or (for the experiments shown in Figs 4 and 6) using Lowry's method. In each case, the standard was dry bovine serum albumin.

Potentiometric titrations. The procedure described by van Wielink et al. (1982) was used with minor modifications. Cytoplasmic membranes were titrated in a medium containing $100 \mathrm{mM}-\mathrm{HEPES}, 15 \mathrm{mM}^{-\mathrm{MgCl}_{2}}$, 4 mM-EDTA, $0.4 \mathrm{M}$-ethanol and the mediators described by van Wielink et al. (1982) with the addition of $12.5 \mu \mathrm{M}$ $N, N, N^{\prime}, N^{\prime}$-tetramethyl-p-phenylene diamine (TMPD). The $\mathrm{pH}$ was $7 \cdot 0$. Titrations were performed at $298 \mathrm{~K}$ in either a $3 \mathrm{ml}$ glass cuvette or a glass vessel (nominal capacity $35 \mathrm{ml}$ ) depending on whether spectra were to be recorded at $298 \mathrm{~K}$ or $77 \mathrm{~K}$, respectively. In either case, the vessel was equipped with a Pt electrode $(1 \times 5 \times$ $20 \mathrm{~mm}$ ), an $\mathrm{Ag} / \mathrm{AgCl}$ reference electrode, a sampling tube, and a line via which the magnetically stirred sample was continuously flushed with argon $\left(\mathrm{O}_{2} \leqslant 0 \cdot 1\right.$ p.p.m.). Reductive titrations were made with additions of a solution of $\mathrm{Na}_{2} \mathrm{~S}_{2} \mathrm{O}_{4}$; in oxidative titrations (always started with a fresh sample), cytochromes were first reduced with $\mathrm{NADH}$ and $\mathrm{Na}_{2} \mathrm{~S}_{2} \mathrm{O}_{4}$ before the stepwise addition of an anoxic solution of $\mathrm{K}_{3} \mathrm{Fe}\left(\mathrm{CN}_{6}\right)$. Potentials were measured with a Philips digital pH/millivolt meter, PW 9408. For spectral analysis at $77 \mathrm{~K}$ of membranes poised at selected potentials, such samples were rapidly and anoxically siphoned into special cuvettes $(1.0 \mathrm{ml}$ capacity, path length $2 \mathrm{~mm}$ ), which were immediately frozen in liquid $\mathrm{N}_{2}$ and used in the low-temperature accessory (J49603, American Instrument Company, 8030 Georgia Ave., Silver Spring, Md. 20910, U.S.A.) of the DW-2a spectrophotometer. Nine scans of each sample were recorded and averaged (see below). Further details of these procedures are given by van Wielink et al. (1982).

Analysis of the titration data. For baseline corrections, calculation of peak areas, and scan averaging, the spectrophotometer was real-time and on-line connected to a PDP 11/03 microcomputer (Digital Equipment Co., Maynard, Mass. 01754, U.S.A.). Spectra were stored in a disc-based minicomputer (Hewlett-Packard 21 M-E with RTE IV-B). Spectra recorded at $77 \mathrm{~K}$ were normalized with respect to spectra at $298 \mathrm{~K}$, recorded at the same redox potential, to overcome the variable optical pathlength of frozen samples. The normalized $77 \mathrm{~K}$ spectra were 
analysed by fitting the following equation, which is based on the Nernst and Gauss equations and describes the absorbance $(A)$ in composite $\alpha$-bands, as a function of wavelength $(\lambda)$ and oxidation-reduction potential $(E)$ :

$$
A(\lambda, E)=\sum_{i=1}^{n} A_{\mathrm{m}, i}^{*}\left[1+\exp \left\{\left(E-E_{0, i}^{\prime}\right) / 25 \cdot 68\right\}\right]^{-1} \exp \left\{-4 \ln 2 \cdot \lambda_{\mathrm{m}, i}^{2}\left(\lambda_{\mathrm{m}, i}-\lambda\right)^{2} / \lambda^{2} \cdot w_{\lambda, i}^{2}\right\}
$$

For each of a given number of components $(n)$, four parameters were optimized:

$A_{\mathrm{m}, i}^{*}$, the absorbance maximum of component $i$ at full reduction,

$E_{\mathrm{o}, i}^{\prime}$, the midpoint potential of component $i$ at $\mathrm{pH} 7 \cdot 0$,

$\lambda_{\mathrm{m}, i}$, the wavelength at the absorption maximum of component $i$,

$w_{\lambda, i}$, the band width of component $i$ at $A=\frac{1}{2} A_{\mathrm{m}, i}$.

The number of components was chosen on the basis of the sum of squared differences between experimental and predicted points.

Fourth-order finite difference and derivative analyses. Two methods were used. In the first, the stored data from the DW-2a spectrophotometer or simulated composite spectra (van Wielink et al., 1982) were analysed according to Savitsky \& Golay (1964), with the correction tables of Steiner et al. (1972). Alternatively, reduced minus oxidized difference spectra recorded at $77 \mathrm{~K}$ in a Unicam SP1700 spectrophotometer with cryogenic accessories were transferred to paper tape at $0 \cdot 1 \mathrm{~nm}$ intervals and analysed using the algorithm of Butler \& Hopkins (1970) as described in detail by Salmon \& Poole (1980) and Poole et al. (1980).

Derivative curves were obtained by taking differences between values a specified number of nm apart (the differencing or differentiating interval referred to in Results and Discussion). Consider the absorbance values at $0.1 \mathrm{~nm}$ intervals to be numbered sequentially $(n)$. The first derivative values $\left(A^{\mathrm{I}}\right)$ were obtained as absorbance differences between points $\omega \mathrm{nm}$ apart, with each computed value assigned to the mid-point of the differencing interval. Thus,

$$
A^{\mathrm{I}}\left(n+\frac{\omega}{2}\right)=A(\omega+n)-A(n)
$$

where the numbers in parentheses indicate the positions of the absorbance or derivative values. Higher derivatives $\left(A^{\mathrm{II}}, A^{\mathrm{III}}, A^{\mathrm{IV}}\right.$, etc.) were obtained by a similar differentiation of the preceding derivative curve (Butler $\&$ Hopkins, 1970). For $A^{\mathrm{IV}}$, a set of four differencing intervals $(\omega, x, y, z)$ that are similar, but not equal, gives less noise. This and other aspects of the choice of intervals are discussed by Butler \& Hopkins (1970) and Butler (1979).

Photodissociation spectra. Membranes were suspended in a buffer that contained $30 \%(\mathrm{v} / \mathrm{v})$ ethylene glycol, and $50 \mathrm{~mm}$-Tris $/ \mathrm{H}_{2} \mathrm{SO}_{4}$ ( $\mathrm{pH} 8.0$ at room temperature) and reduced with $1 \mathrm{mM}-\mathrm{NADH}$ or $2 \mathrm{~mm}$-ascorbate $+0 \cdot 1 \mathrm{~mm}-$ TMPD. The low temperature protocol was essentially that described previously (Poole et al., 1979; Poole \& Chance, 1981). Flash photolysis was achieved in the sample compartment of a microprocessor-controlled Johnson Foundation dual-wavelength spectrophotometer, by means of a xenon lamp.

Chemicals. The sources of redox mediators are given by van Wielink et al. (1982). Yeast extract was from Difco and proteose peptone from Oxoid. All other chemicals were of the highest purity available.

\section{RESULTS AND DISCUSSION}

\section{Combined potentiometric and spectral analysis at $298 \mathrm{~K}$}

A redox titration of the $\alpha$-bands of $b, c$ and $a$-type cytochromes is shown in Fig. 1. At this temperature, the area-potential relationship reveals that at least three $b$ - and/or $c$-type cytochromes contribute to the 540 to $580 \mathrm{~nm}$ region and that the $a$-type cytochromes absorbing at about $600 \mathrm{~nm}$ may be resolved into two components. The parameters from this type of analysis are shown in Table 1 . Three major components contributing to the cytochrome $b$ and $c$ region have midpoint potentials of +209 , +20 and $-166 \mathrm{mV}$, respectively, whilst the cytochrome oxidase region is resolved into components of +363 and $+202 \mathrm{mV}$. Clearly, in a group of overlapping absorption bands, the goodness of fit between the experimental and predicted points will appear to improve as the number of presumptive components fitted to the data is increased. The analysis was terminated, therefore, when the sum of squared differences between the experimental and predicted points did not improve significantly when the number of components was increased further. In the case of analysis of the area-potential relationship (Fig. 1), the sums of squared differences (in arbitrary units) for fits of one, two, three, four and five components to the data were $205 \cdot 8,22 \cdot 1,6 \cdot 3,4 \cdot 7$ and $6 \cdot 0$, respectively. The threecomponent fit was therefore adopted, although the narrower band widths of components at $77 \mathrm{~K}$ allow greater resolution at this temperature (see below). 


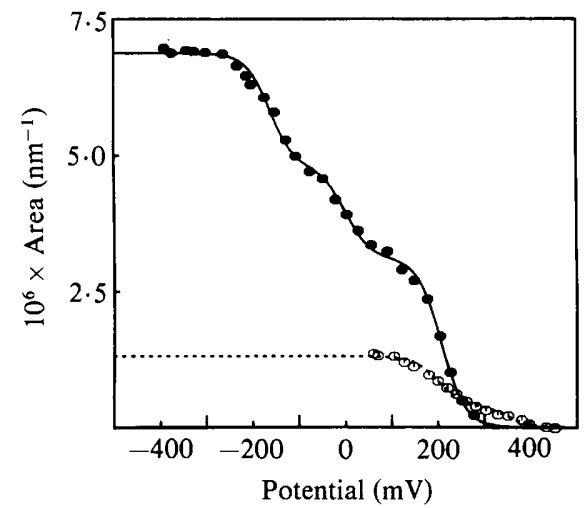

Fig. 1. Potentiometric titration of the $b$-type, $c$-type and $a$-type cytochromes in membranes at $298 \mathrm{~K}$. Peak areas of the $\alpha$-bands of the $b$-type plus $c$-type cytochromes $(O)$ and of the $a$-type cytochromes $(O)$ are plotted versus the redox potential. The redox potential was varied by the addition of NADH, dithionite or ferricyanide in the presence of mediators (see Methods). The protein concentration was $4.8 \mathrm{mg} \mathrm{ml}^{-1}$. The solid line represents the best fit analyses for the titration of cytochromes $b$ and $c$ (three components) whilst the dotted line is the best fit for the $a$-type cytochromes (two components). Further details of the resolved components are given in Table 1.

Table 1. Best-fitting parameters for the potentiometric titrations at $298 \mathrm{~K}$ of the $\alpha$-bands of cytochromes in PS3 cytoplasmic membranes

Percentage area expresses the proportional contribution of a component to the area occupied by the optical absorbance band, $E_{\mathrm{m}, 7}$ is the midpoint potential of the component at $\mathrm{pH} 7 \cdot 0, \lambda_{\mathrm{m}}$ is the position of the absorbance maximum and $w_{\lambda}$ is the band width at half-height. All values are means of two titrations with standard errors in parentheses.

\begin{tabular}{|c|c|c|c|c|c|c|}
\hline \multirow[b]{2}{*}{ Cytochromes } & \multicolumn{2}{|c|}{$\begin{array}{l}\text { From area-potential } \\
\text { relationship }\end{array}$} & \multicolumn{4}{|c|}{$\begin{array}{l}\text { From deconvolution of spectra } \\
\text { recorded at poised redox potentials }\end{array}$} \\
\hline & $\begin{array}{c}\text { Percentage } \\
\text { area }\end{array}$ & $\begin{array}{l}E_{\mathrm{m}, 7} \\
(\mathrm{mV})\end{array}$ & $\begin{array}{l}\text { Percentage } \\
\text { area }\end{array}$ & $\begin{array}{c}\lambda_{\mathrm{m}} \\
(\mathrm{nm})\end{array}$ & $\begin{array}{c}w_{\lambda} \\
(\mathrm{nm})\end{array}$ & $\begin{array}{l}E_{\mathrm{m}, 7} \\
(\mathrm{mV})\end{array}$ \\
\hline \multirow[t]{3}{*}{$b+c$} & $47(4)$ & +209 & $45(3)$ & $550.9(0.4)$ & $9.9(0 \cdot 2)$ & $+209(0)$ \\
\hline & $22(2)$ & $+20(29)$ & $25(3)$ & $559.8(0.9)$ & $12 \cdot 1(2 \cdot 0)$ & $+33(33)$ \\
\hline & $29(1)$ & $-166(4)$ & $30(1)$ & $562(0 \cdot 2)$ & $12 \cdot 0(0 \cdot 5)$ & $-166(8)$ \\
\hline \multirow{2}{*}{$a+a_{3}$} & $33(3)$ & $+363(18)$ & $40(10)$ & $600(4)$ & $21(6)$ & $+340(15)$ \\
\hline & $67(3)$ & $+202(6)$ & $60(10)$ & $603(2)$ & $17(3)$ & $+190(10)$ \\
\hline
\end{tabular}

A combined analysis of the potentiometric and spectral data (Fig. 2) revealed that the highpotential component in the 537 to $575 \mathrm{~nm}$ region was a $c$-type cytochrome $\left(\lambda_{\mathrm{m}}=550.9 \mathrm{~nm}\right.$; Table 1) whilst the absorption maxima of the other two components $(559.8$ and $562 \mathrm{~nm})$ were appropriate for $b$-type cytochromes. In the 580 to $625 \mathrm{~nm}$ region, the two broad components were shown to be separated by only $3 \mathrm{~nm}$ (600 and $603 \mathrm{~nm}$, respectively).

\section{Combined potentiometric and spectral analysis at $77 \mathrm{~K}$}

The value of recording cytochrome spectra at $77 \mathrm{~K}$ is well documented (Chance, 1957; Estabrook, 1961; Wilson, 1967) and will not be reiterated here. The most dramatic effect of lowered temperature was the splitting of the $550.9 \mathrm{~nm}$ band seen at room temperature (Fig. 2; Table 1) into components at approximately 547 and $552 \mathrm{~nm}$ (Fig. 3; Table 2). A band at $547 \mathrm{~nm}$ or $548 \mathrm{~nm}$ is clearly visible in $77 \mathrm{~K}$ difference spectra (Poole, 1981) without recourse to deconvolution techniques. This band and the $552 \mathrm{~nm}$ band titrate with potentials similar to each other (Table 2) and to mitochondrial cytochrome $c$ (Dutton \& Wilson, 1974), making it likely that they arise from a single $c$-type cytochrome with a split $\alpha$-band, although the possibility that there are at least two spectrally distinct, but potentiometrically similar, cytochromes $c$ cannot be 


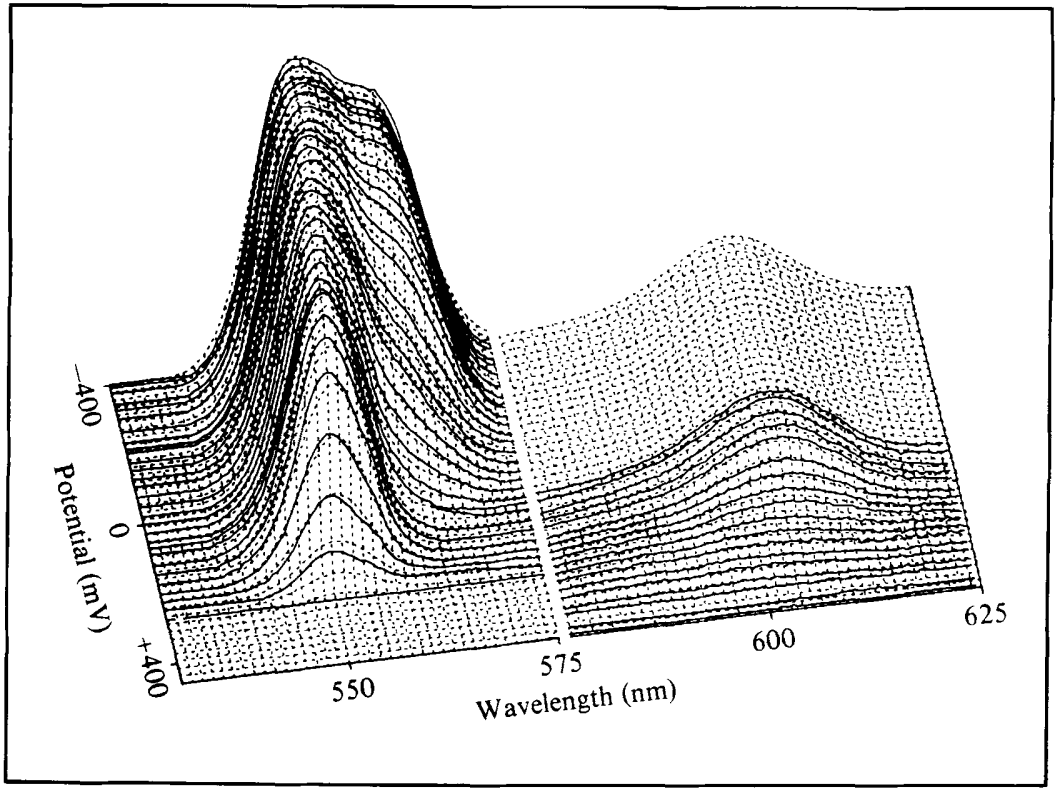

Fig. 2. Three-dimensional plot of spectra of the cytochromes in membranes poised at different redox potentials at $298 \mathrm{~K}$. The absorbance is plotted perpendicular to the plane determined by the wavelength and potential axes. The solid lines are spectra recorded at different redox potentials at $298 \mathrm{~K}$ as described in Methods. The reticular broken lines represent the best-fitting three-component solution for the $b$ - and $c$-type cytochromes (530 to $575 \mathrm{~nm}$ ) and the best two-component solution for the $a$-type cytochromes $(575$ to $625 \mathrm{~nm})$. In this particular titration, the computed values for $\lambda_{\mathrm{m}}, w_{\lambda}$, and $E_{\mathrm{m}, 7}$, respectively, in the 530 to $575 \mathrm{~nm}$ region, were: $550.6 \mathrm{~nm}, 9.8 \mathrm{~nm},+208 \mathrm{mV} ; 559.2 \mathrm{~nm}, 13.6 \mathrm{~nm}$, $+8 \mathrm{mV} ; 561.9 \mathrm{~nm}, 12.1 \mathrm{~nm},-166 \mathrm{mV}$. The corresponding values for the 575 to $625 \mathrm{~nm}$ region were: $597.3 \mathrm{~nm}, 26.7 \mathrm{~nm},+345 \mathrm{mV} ; 603.9 \mathrm{~nm}, 16.1 \mathrm{~nm},+200 \mathrm{mV}$. Protein concentration was $4.8 \mathrm{mg} \mathrm{ml}^{-1}$.

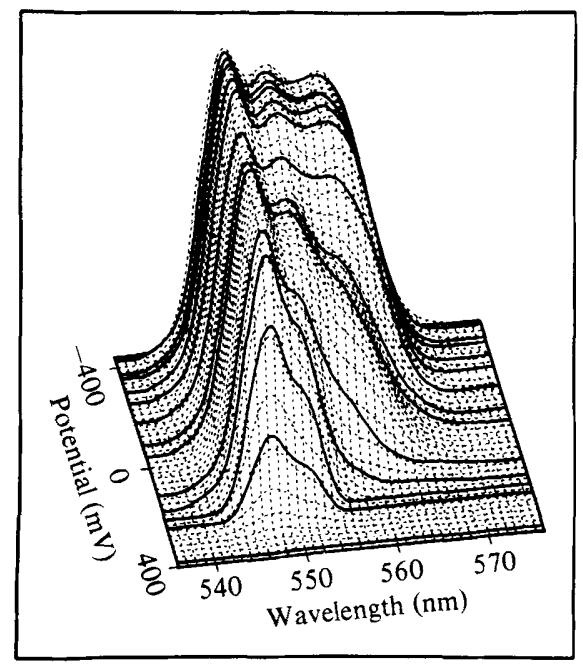

Fig. 3. Three-dimensional plot of spectra of the cytochromes in membranes poised at different redox potentials and then trapped and measured at $77 \mathrm{~K}$. Presentation is as in Fig. 3. The solid lines are spectra recorded after trapping at $77 \mathrm{~K}$ samples from a $298 \mathrm{~K}$ redox titration as described in Methods. The reticular broken lines represent the best-fitting solution for five components; full details of the parameters are given in Table 2 . 
Table 2. Sets of best-fitting parameters obtained from deconvolution of $77 \mathrm{~K}$ spectra of the $\alpha$ bands of $b$ - and c-type cytochromes in PS3 cytoplasmic membranes

The parameters have the same meanings as in Table 1. A chi-square test for each set gave values of 98 , 47 and $\mathbf{4 0}$ for four, five and six components, respectively. Components that are regarded as equivalent (in terms of $\lambda_{\mathrm{m}}$ and $E_{0}^{*}$ ) in the three solutions are shown on the same line.

\begin{tabular}{|c|c|c|c|}
\hline \multicolumn{4}{|c|}{ Four-component fit } \\
\hline $\begin{array}{c}\text { Percentage } \\
\text { area }\end{array}$ & $\begin{array}{c}\lambda_{\mathrm{m}} \\
(\mathrm{nm})\end{array}$ & $\begin{array}{c}w_{\lambda} \\
(\mathrm{nm})\end{array}$ & $\begin{array}{l}E_{\mathrm{m}, 7} \\
(\mathrm{mV})\end{array}$ \\
\hline 30 & $547 \cdot 3$ & $5 \cdot 4$ & \\
\hline 14 & $552 \cdot 1$ & $4 \cdot 7$ & +2 \\
\hline 28 & 557.7 & $9 \cdot 7$ & +10 \\
\hline 29 & 558.4 & 11.4 & -165 \\
\hline
\end{tabular}

$\begin{array}{ccrc}\begin{array}{c}\text { Percentage } \\ \text { area }\end{array} & \begin{array}{c}\lambda_{\mathrm{m}} \\ (\mathrm{nm})\end{array} & \begin{array}{c}w_{i} \\ (\mathrm{~nm})\end{array} & \begin{array}{c}E_{\mathrm{m}, 7} \\ (\mathrm{mV})\end{array} \\ 27 & 547 \cdot 2 & 5 \cdot 2 & +229 \\ 13 & 552 \cdot 0 & 4 \cdot 9 & +221 \\ 27 & 556.9 & 9 \cdot 3 & +104 \\ 16 & 560.8 & 7.9 & -130 \\ 17 & 554.4 & 13.9 & -194\end{array}$

$\begin{array}{ccrc}\begin{array}{c}\text { Percentage } \\ \text { area }\end{array} & \begin{array}{c}\lambda_{\mathrm{m}} \\ (\mathrm{nm})\end{array} & \begin{array}{c}w_{\lambda} \\ (\mathrm{nm})\end{array} & \begin{array}{c}E_{\mathrm{m}, 7} \\ (\mathrm{mV})\end{array} \\ 27 & 547.2 & 5.2 & +230 \\ 13 & 552.0 & 4.9 & +221 \\ 27 & 556.9 & 9.4 & +105 \\ 17 & 560 \cdot 3 & 8.4 & -123 \\ 15 & 553.8 & 14.0 & -197 \\ 2 & 562.9 & 4.3 & -350\end{array}$

discounted. The band widths are also almost identical. The cytochrome $c$ that copurifies with cytochrome oxidase $a a_{3}$, and has $\lambda_{\max }$ of $550 \mathrm{~nm}$ at room temperature (Sone et al., 1979; Sone \& Yanagita, 1982) presumably contributes to, or is, the $547 \mathrm{~nm}$ component at $77 \mathrm{~K}$.

The three solutions shown in Table 2 each reveal the presence of a component with an absorption maximum at 556.9 to 557.7 , which is probably a $b$-type cytochrome. Additional components are seen at $558.4 \mathrm{~nm}$ in the four-component fit, at 560.8 and $554.4 \mathrm{~nm}$ in the fivecomponent fit, and at $560.3,553.8$ and $562.9 \mathrm{~nm}$ in the six-component fit. An unequivocal decision between these solutions is problematic, although the fit of the experimental spectra to the predicted is little improved on increasing the number of components from five to six (as assessed in a chi-square test, Table 2).

The most important fact that argues against accepting the four-component model is its failure to reveal a peak at about $554 \mathrm{~nm}$ (Fig. 3; Table 2), in spite of the sharp trough at 553 to $554 \mathrm{~nm}$ consistently seen in $\mathrm{CO}+$ reduced or $\mathrm{CN}^{-}+$reduced minus reduced difference spectra at $77 \mathrm{~K}$ (Poole, 1981; this paper, Fig. 6d). A shoulder is also visible at about $554 \mathrm{~nm}$ in NO difference spectra. The components at about 547,552 and $557 \mathrm{~nm}$ in all three solutions also coincide with peaks seen in the spectra of Poole (1981). Further evidence against the four-component model is that the longest wavelength maximum is seen at $558.4 \mathrm{~nm}$. At room temperature, $30 \%$ of the total absorbance area is due to a $562 \mathrm{~nm}$ component which would thus have to be shifted by almost $4 \mathrm{~nm}$ on lowering the temperature. This shift is somewhat greater than would normally be expected ( 2 to $3 \mathrm{~nm}$; Salmon \& Poole, 1980). The five-component model satisfies the existence of a peak at 552 to $554 \mathrm{~nm}$ and introduces a peak at $560.8 \mathrm{~nm}$, which could correspond with the $562 \mathrm{~nm}$ peak at room temperature. In addition, a peak at $560.5 \mathrm{~nm}$ is seen in fourth-order finite difference analyses (see below). The essential difference between the five- and six-component solutions is the presence in the latter of a component of very low midpoint potential and narrow band width at about $563 \mathrm{~nm}$.

\section{Fourth-order finite difference and derivative analyses of spectra recorded at $77 \mathrm{~K}$}

By effectively diminishing the band width of individual components in a composite spectrum, fourth-order finite difference (e.g. Salmon \& Poole, 1980; Scott \& Poole, 1982) and derivative analyses allow increased resolution of the number of components present. As a sole approach to spectral deconvolution, these techniques should be used with caution (Morrey, 1968; Butler, 1979; Meister, 1982) because of the possibility of introducing artefactual components. However, when the spectrum for analysis is relatively noise-free, and differencing intervals are carefully chosen, such spectra should correspond with independently derived solutions to complex spectra. In addition, the fourth derivative analysis of the experimental data and of the deconvolution selected on potentiometric grounds should be comparable.

Figures 4 and 5 compare the numerical analyses of spectra of reduced membranes obtained using either the Butler \& Hopkins (1970) algorithm or the method of Savitsky \& Golay (1964). 


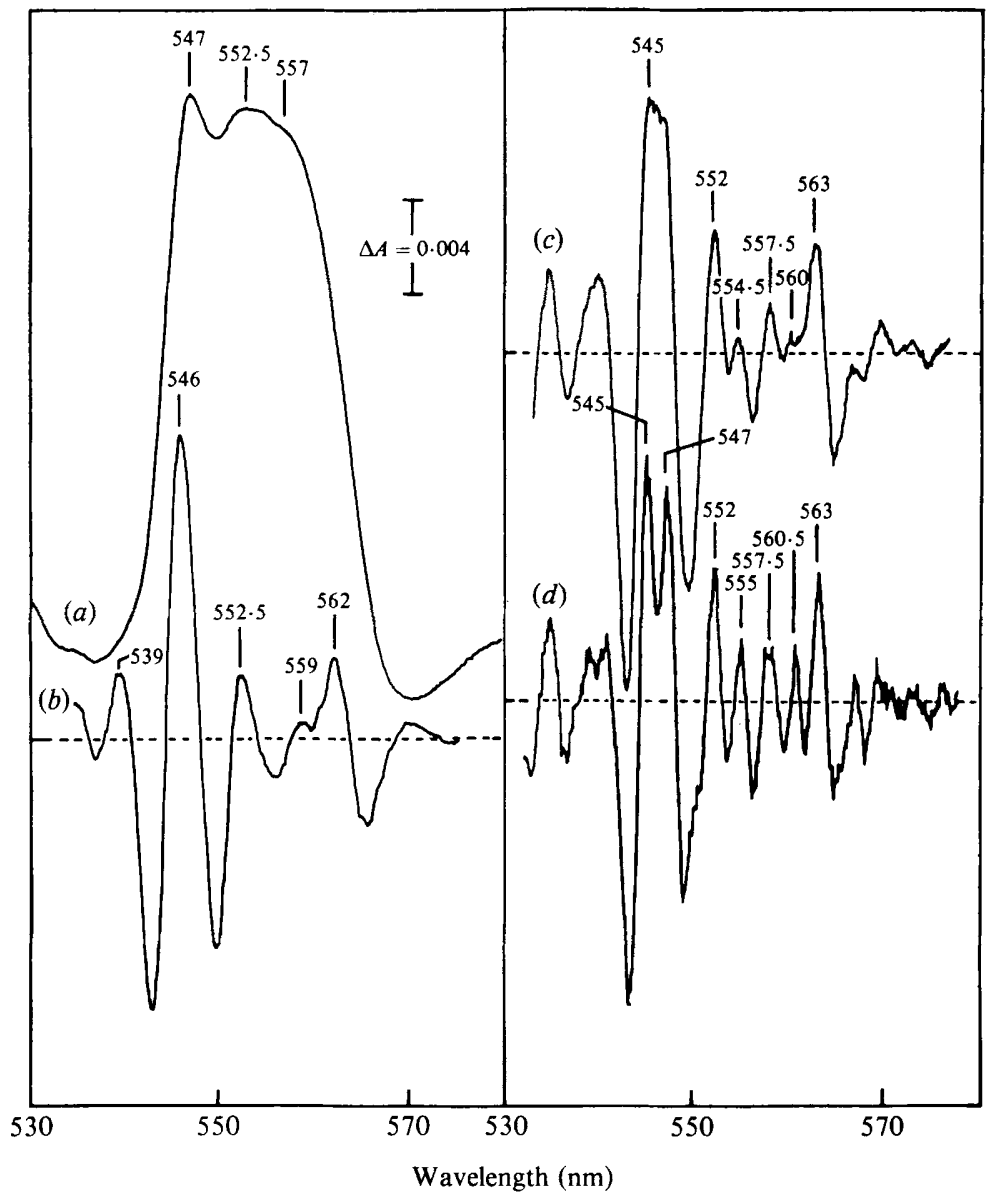

Fig. 4. Reduced minus oxidized difference spectrum of $b$ - and $c$-type cytochromes and its fourth-order finite difference analysis using the algorithm of Butler \& Hopkins (1970). Spectrum $(a)$ is the sum of four spectra recorded at $77 \mathrm{~K}$ under the following conditions: spectral band width, $0.9 \mathrm{~nm}$; scan rate, $0.2 \mathrm{~nm} \mathrm{~s}^{-1}$; data sampling, $2 \mathrm{~s}^{-1}$; protein concentration, $7 \mathrm{mg} \mathrm{ml}^{-1}$; path length, $2 \mathrm{~mm}$. The differencing intervals used for numerical analyses were : (b) $2 \cdot 5,2 \cdot 3,2 \cdot 2,2 \cdot 1 \mathrm{~nm} ;(c) 1 \cdot 8,1 \cdot 6,1 \cdot 5,1 \cdot 4 \mathrm{~nm}$; (d) $1.4,1 \cdot 2,1 \cdot 1,1.0 \mathrm{~nm}$. Dashed lines represent zero absorbance in the numerical analyses.

Figure $4(a)$ shows the $\mathrm{Na}_{2} \mathrm{~S}_{2} \mathrm{O}_{4}$-reduced minus oxidized difference spectrum used for analysis; note the high signal-to-noise ratio of the summed spectra. The $547 \mathrm{~nm}$ peak is clearly resolved but at higher wavelengths individual maxima are not observed. At successively smaller differencing intervals (Fig. $4 b$ to $d$ ), greater complexity is revealed. At the largest differencing intervals used (Fig. $4 b$ ), four of the six components of Table 2 are already seen. At smaller intervals (Fig. 4c) there is excellent correspondence in the number and positions of peaks with the six-component model. With the exception of the largest and broadest peak, the labelled absorption maxima in this analysis and those in the six-component fit of Table 2 vary only by 0 to $1.0 \mathrm{~nm}$. The intensity of the 562 to $563 \mathrm{~nm}$ component in all the derivative analyses of Fig. 4 is presumably a consequence of its very narrow band width (Table 2), since the algorithm discriminates strongly in favour of such bands (Butler \& Hopkins, 1970). The potentiometric analysis (Table 2 ) suggests that it contributes only $2 \%$ of the total spectral area. Similarly, the low intensity of the 554 to $555 \mathrm{~nm}$ component in Fig. 4(c), which is seen most clearly at the smallest intervals (Fig. $4 d$ ), probably results from the broadness of this band revealed in both the potentiometric analysis (Table 2) and the flash photolysis studies (Fig. 6, see later). In Fig. $4(d)$ the broad $545 \mathrm{~nm}$ band is split to reveal the $547 \mathrm{~nm}$ band (Table 2; Fig. $4 a$ ); the significance of this is unclear. 


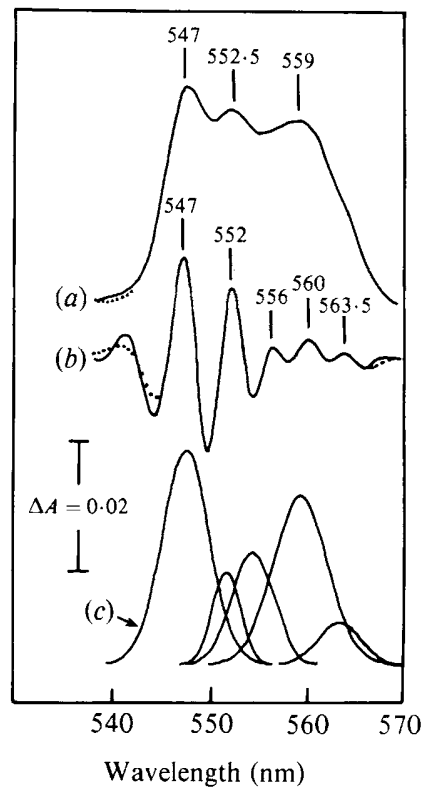

Fig. 5. Fourth derivative spectrum of membranes poised at $-424 \mathrm{mV}$ and then trapped at $77 \mathrm{~K}$. Spectrum ( $a$ ) (solid line) is the experimental spectrum recorded as described in Methods. Its fourth derivative is the solid line, curve $(b)$. The five component curves of $(b)$, one of which is labelled $(c)$, are also shown. The dotted line seen on $(a)$ at about $540 \mathrm{~nm}$ shows the simulated spectrum based on the resolved five components; in other regions of the spectrum, the simulated and actual spectra were superimposed. The dotted lines at either end of $(b)$ show the fourth derivative of the simulated spectrum where this was not superimposed on the experimental spectrum. The absorbance maxima of the resolved components in (c) and (in parentheses) the percentage area and band width, respectively, are: $547 \cdot 3 \mathrm{~nm}(35 \cdot 6,5 \cdot 75 \mathrm{~nm}), 551 \cdot 6 \mathrm{~nm}(9 \cdot 12,3 \cdot 40 \mathrm{~nm}), 554 \cdot 3 \mathrm{~nm}(16 \cdot 25,5 \cdot 01 \mathrm{~nm}), 559 \cdot 2 \mathrm{~nm}(32 \cdot 6,6 \cdot 69 \mathrm{~nm})$ and $563 \cdot 4 \mathrm{~nm}(6 \cdot 05.5 \cdot 02 \mathrm{~nm})$.

Figure 5 shows the fourth derivative analysis of Savitsky \& Golay (1964). A five-component fit of the original spectrum is almost indistinguishable from the fit of the simulated spectrum constructed from the five presumptive components (Table 2). The components found correspond well with those in Fig. 4(c) and $(d)$ although the $557.5 \mathrm{~nm}$ band is missing; this, like the $554 \mathrm{~nm}$ band, is rather broad (Table 2). Apart from minor differences $(0 \cdot 1$ to $1.0 \mathrm{~nm})$ in band positions, this analysis, like that in Fig. 4 is in good agreement with the six-component fit of Table 2.

\section{CO-binding cytochromes and photodissociability}

Bubbling a suspension of reduced membranes with $\mathrm{CO}$ for $2.5 \mathrm{~min}$ led to small decreases in the absorbances of $a-, b$ - and $c$-type cytochromes (Fig. $6 a, b$ ). Note that the intensity of the cytochrome oxidase $\left(a a_{3}\right)$ band at about $603 \mathrm{~nm}$ is diminished by only about $10 \%$, in agreement with previous results (Poole, 1981). A simplistic interpretation is that cytochrome $a_{3}$ (by definition the ligand-binding component of the complex) makes only a small contribution to this region of the spectrum. Alternatively (see Wikstrom et al., 1976), the slight decrease in intensity on ligand binding is due to a decrease in the extinction coefficient of cytochrome $a$ as a result of haem-haem interaction. This interaction also explains the close similarity of the midpoint potentials of this band, reduction of one haem forcing the other into a high spin state with a drastically decreased affinity of the latter for an electron (decrease in $E_{\mathrm{m}}$ ).

The difference spectrum (reduced minus $\mathrm{CO}+$ reduced, Fig. $6 c$ ) reveals more clearly ligandbinding cytochromes of the $c$ - $(547 \mathrm{~nm}), b$ - $(428$ and $555 \mathrm{~nm})$ and $a$-type $(443$ and $602 \mathrm{~nm})$. The photodissociation spectrum (Fig. $6 d$ ) also shows (as peaks) the positions of ferrocytochromes that form photodissociable compounds with $\mathrm{CO}$ and (as troughs) the positions of these 


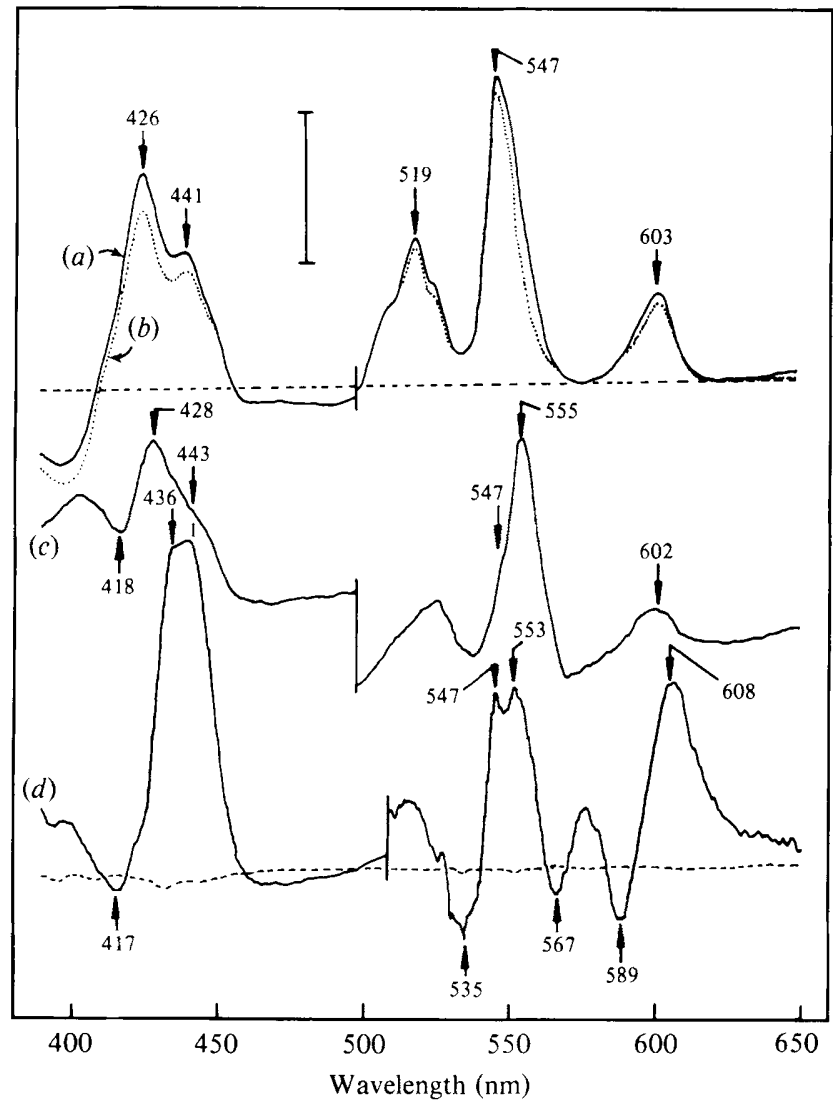

Fig. 6. CO-binding cytochromes in membranes from PS3. Spectrum $(a)$ is a reduced (with ascorbate + TMPD) minus oxidized (with ammonium persulphate) difference spectrum; in ( $b$; dotted line) the reduced sample was then bubbled with $\mathrm{CO}$ for $2.5 \mathrm{~min}$ before recording the $\mathrm{CO}$-reduced minus oxidized spectrum. The dashed line is an oxidized minus oxidized baseline. Spectrum $(c)$ is a computed difference between the reduced and CO-reduced spectra used in $(a)$ and $(b)$. Spectra $(a)$ to $(c)$ were recorded at $173 \mathrm{~K}$. Spectrum $(d)$ was obtained by recording and storing the spectrum of an NADH-reduced plus $\mathrm{CO}$ sample (the dashed line is the $\mathrm{CO}$-reduced minus $\mathrm{CO}$-reduced baseline) and then photolysing the sample at $170 \mathrm{~K}$ with 25 flashes from a xenon lamp, to give the photolysed (= reduced) minus $\mathrm{CO}$-reduced difference spectrum. The vertical bar represents the following $\triangle A$ (below and above about $500 \mathrm{~nm}$ respectively): (a), (b) 0.29 and $0.145 ;(c) 0.073$ and $0.029 ;(d) 0.029$ and 0.0145 . The protein concentration in $(a)$ to $(c)$ was $1.52 \mathrm{mg} \mathrm{ml}^{-1}$, and in $(d), 3.2 \mathrm{mg} \mathrm{ml}^{-1}$.

compounds. Such spectra identify cytochrome $a_{3}$ with absorption maxima in the reduced form at about 443 and $605 \mathrm{~nm}$. The CO compound absorbs at $589 \mathrm{~nm}$. These positions are close to those found for mitochondrial cytochrome $c$ oxidase (Wikstrom et al., 1976).

The troughs at 417, 535 and $567 \mathrm{~nm}$ are characteristic of the CO complex of cytochrome $o$. Identification of the $\alpha$-peak of its reduced form with one of the components resolved in Table 2 is more problematic, however, since the positions of cytochrome $o$ bands ( 555 to $565 \mathrm{~nm}$; Lemberg \& Barrett, 1973) and their midpoint potentials are extremely variable, e.g. from $-30 \mathrm{mV}$ for Azotobacter vinelandii (Yang, 1981) to $+210 \mathrm{mV}$ for Paracoccus denitrificans (Willison et al., 1981). Vitreoscilla cytochrome $o$ contains haems with different midpoint potentials $(-122$ and $+118 \mathrm{mV}$; Tyree \& Webster, 1978), further complicating analysis.

The peak at $547 \mathrm{~nm}$ in Fig. $6(d)$ suggests that the CO complex of a $c$-type cytochrome is photodissociable, although photochemical action spectra (Poole et al., 1982) do not indicate an oxidase function for this component. Although CO-binding cytochromes $c$ are widely distributed in bacteria (Iwasaki \& Shidara, 1969; Tonge et al., 1974), their function (or 
functions) is unclear. Only a few, such as that in Beneckea natriegens (Weston \& Knowles, 1973) are similar to the PS3 cytochrome in having a high midpoint potential and being membranebound.

Prolonged incubation $(90 \mathrm{~min}$ ) of reduced membranes in an atmosphere of $\mathrm{CO}$ (results not shown) led to the formation of a peak (in reduced minus reduced + CO spectra) at $554 \mathrm{~nm}$, together with a new band at $563 \mathrm{~nm}$; the latter could have arisen from CO binding to partially denatured cytochrome $b$ (Ben-Gershom, 1961). Under these conditions, the intensity of the cytochrome $a a_{3}, \alpha$-peak was again diminished by only approximately $10 \%$.

\section{Conclusions}

We have adopted an integrated approach to study the complex membrane-bound cytochromes of aerobically grown PS3. The main advantages of the method (van Wielink et al., 1982) are (a) the simultaneous characterization of each component with respect to its midpoint potential and spectral properties, and (b) the constancy in the characteristics of the components resolved as more components are introduced, major and minor peaks being resolved sequentially.

The most satisfactory interpretation of the spectral deconvolution at $77 \mathrm{~K}$ is that five $b$-and/or $c$-type cytochromes contribute to the $\alpha$ region. These are $c$-type cytochromes at (i) $547 \mathrm{~nm}$ $(+229 \mathrm{mV})$ and (ii) $552 \mathrm{~nm}(+221 \mathrm{mV})$ and $b$-type cytochromes at (iii) $554 \mathrm{~nm}(-194 \mathrm{mV})$, (iv) $557 \mathrm{~nm}(+104 \mathrm{mV})$ and (v) $561 \mathrm{~nm}(-130 \mathrm{mV})$ (Table 2). The existence of these components is strongly supported by (a) fourth derivative and (b) fourth-order finite difference analyses. On the basis of the midpoint potentials, $b_{557 \mathrm{~nm}}$ is tentatively identified as the CO-binding cytochrome oxidase $o$.

The $\alpha$-band of the $a$-type cytochrome oxidase at 600 to $605 \mathrm{~nm}$ is due mostly to cytochrome $a$ but is a composite of two potentiometrically distinct haems. Despite difficulties in explaining the ligand-binding properties of this oxidase, the important point is that, potentiometrically and spectrally, the $a$-type oxidase of this bacterium closely resembles the mitochondrial enzyme, fully justifying efforts to characterize further its relatively simple subunit composition and exploit this feature in studies of the mechanism of oxygen reduction and proton pumping.

R.K.P. thanks the Travel Fund of Queen Elizabeth College for a grant and Professor A. H. Stouthamer and colleagues at the Vrije Universiteit for their hospitality. Dr T. Oshima provided valuable information on growth and maintenance of PS3, while Professor B. Chance provided facilities and encouragement for the flash photolysis experiments. The S.E.R.C. are thanked for grant GR/B/8503.6 to R.K.P.

\section{REFERENCES}

BEN-GERSHOM, E. (1961). Use of carbon monoxide for detecting denaturation in haemoproteins. Biochemical Journal 78, 218-223.

ButLER, W. L. (1979). Fourth derivative spectra.Methods in Enzymology 56, 505-515.

Butler, W. L. \& Hopkins, D. W. (1970). An analysis of fourth derivative spectra. Photochemistry and Photobiology 12, 451-456.

Chance, B. (1957). Techniques for the study of the respiratory enzymes. Methods in Enzymology 4, 273329.

DutTon, P. L. \& WiLson, D. F. (1974). Redox potentiometry in mitochondrial and photosynthetic bioenergetics. Biochimica et biophysica acta 346, 165212.

ESTABROOK, R. W. (1961). Spectrophotometric studies of cytochromes cooled in liquid nitrogen. In Haematin Enzymes, vol. 19, pp. 436-460. Edited by J. E. Falk, R. Lemberg \& R. K. Morton. Oxford: Pergamon Press.

Fee, J. A., Findling, K. L., Lees, A. \& Yoshida, T.
(1978). Respiratory proteins of some extremely thermophilic bacteria. In Frontiers of Biological Energetics, vol. 1, pp. 118-126. Edited by P. L. Dutton, J. S. Leigh \& A. Scarpa. New York: Academic Press.

Goto, K., Hirata, H. \& Kagawa, Y. (1980). A stable $\mathrm{Na}^{+} / \mathrm{H}^{+}$antiporter of thermophilic bacterium PS3. Journal of Bioenergetics and Biomembranes 12, 297308.

HENRY, M. F. \& Vignais, P. M. (1979). Induction by cyanide of cytochrome $d$ in the plasma membrane of Paracoccus denitrificans. FEBS Letters 100, 41-46.

Herbert, D., Phipps, P. J. \& Strange, R. E. (1971). Chemical analysis of microbial cells. Methods in Microbiology 5B, 209-344.

IWASAKI, H. \& ShIDARA, S. (1969). Crystallization of cytochrome $c$-553 in aerobically grown Pseudomonas denitrificans. Journal of Biochemistry 66, 775-781.

LEMBERG, R. \& BARRETT, J. (1973). Bacterial cytochromes and cytochrome oxidases. In Cytochromes, pp. 217-236. London \& New York: Academic Press. 
Ludwig, B. (1980). Heme $a a_{3}$-type cytochrome $c$ oxidases from bacteria. Biochimica et biophysica acta 594, 177-189.

MEISTER, A. (1982). Limits for decomposition of spectra into single bands. Journal of Theoretical Biology 94, 541-553.

MoRREY, J. R. (1968). On determining spectral peak positions from composite spectra with a digital computer. Analytical Chemistry 40, 905-914.

Poole, R. K. (1981). Ligand-binding cytochromes $a_{3}, c$ and $o$ in membranes from the thermophilic bacterium PS3. FEBS Letters 133, 255-259.

PoOle, R. K. \& Chance, B. (1981). The reaction of cytochrome $o$ in Escherichia coli $\mathrm{K} 12$ with oxygen. Evidence for a spectrally and kinetically distinct cytochrome $o$ in cells from oxygen-limited cultures. Journal of General Microbiology 126, 277-287.

Poole, R. K., Waring, A. J. \& Chance, B. (1979). The reaction of cytochrome $o$ in Escherichia coli with oxygen. Low-temperature kinetic and spectral studies. Biochemical Journal 184, 379-389.

Poole, R. K., Scott, R. I. \& Chance, B. (1980). Lowtemperature spectral and kinetic properties of cytochromes in Escherichia coli $\mathrm{K} 12$ grown at lowered oxygen tension. Biochimica et biophysica acta 591, $471-482$

Poole, R. K., Scott, R. I., Baines, B. S., Salmon, I. \& LLOYD, D. (1982). Identification of cytochromes $o$ and $a_{3}$ as functional terminal oxidases in the thermophilic bacterium, PS3. FEBS Letters 150, 281--285.

Salmon, I. \& PoOLE, R. K. (1980). The mitochondrial cytochromes of an unusual budding yeast, Sterigmatomyces halophilus: spectral characterization exploiting fourth-order finite difference analysis. Journal of General Microbiology 117, 315-326.

SAPSHEAD, L. M. \& WimpenNY, J. W. T. (1972). The influence of oxygen and nitrate on the formation of the cytochrome pigments of the aerobic and anaerobic respiratory chain of Micrococcus denitrificans. Biochimica et biophysica acta 267, 388-397.

Savitsky, A. \& Golay, J. E. (1964). Smoothing and differentiation of data by simplified least squares procedures. Analytical Chemistry 36, 1627-1639.

SCOTT, R. I. \& Poole, R. K. (1982). A re-examination of the cytochromes of Escherichia coli using fourthorder finite difference analysis: their characterization under different growth conditions and accumulation during the cell cycle. Journal of General Microbiology 128, 1685-1696.

Sone, N. \& Yanagita, Y. (1982). A cytochrome $a a_{3}$ - type terminal oxidase of a thermophilic bacterium. Purification, properties and proton pumping. Biochimica et biophysica acta 682, 216-226.

Sone, N., OHyama, T. \& KaGawa, Y. (1979). Thermostable single band cytochrome oxidase. FEBS Letters 106, 39-42.

Steiner, J., Termonia, Y. \& Deltour, J. (1972). Comments on smoothing and differentiation of data by simplified least squares procedure. Analytical Chemistry 44, 1906-1909.

Tonge, G. M., Knowles, C. J., Harrison, D. E. F. \& HigGins, I. J. (1974). Metabolism of one carbon compound. Cytochromes of methane- and methanolutilizing bacteria. FEBS Letters 44, 106-110.

TYREE, B. \& WeBSTER, D. A. (1978) Electron-accepting properties of cytochrome $o$ purified from Vitreoscilla. Journal of Biological Chemistry 253, 7635-7637.

Weston, J. A. \& Knowles, C. J. (1973). A soluble CObinding $c$-type cytochrome from the marine bacterium Beneckea natriegens. Biochimica et biophysica acta 305, 11-18.

VAN Wielink, J. E., OltManN, L. F., LeEuWerik, F. J. DE Hollander, J. A. \& Stouthamer, A. H. (1982). A method for in situ characterisation of $b$ - and $c$-type cytochromes in Escherichia coli and in Complex III from beef heart mitochondria by combined spectrum deconvolution and potentiometric analysis. Biochimica et biophysica acta 681, 177-190.

WiKSTROM, M. K. F., HARMON, H. J., INGLEDEW, W. J, \& CHANCE, B. (1976). A re-evaluation of the spectral, potentiometric and energy-linked properties of cytochrome $c$ oxidase in mitochondria. FEBS Letters $\mathbf{6 5}$, 259-277.

Willison, J. C., INGLEDEW, W. J. \& HADDOCK, B. A. (1981). The membrane-bound cytochromes of Paracoccus denitrificans: a potentiometric analysis of different phenotypes. FEMS Microbiology Letters 10 , 363-368.

WILSON, D. F. (1967). Effect of temperature on the spectral properties of some ferrocytochromes. Archives of Biochemistry and Biophysics 121, 757-768.

YANG, T. (1981). Oxidation-reduction titration of cytochrome components in the electron transport chain of Azotobacter vinelandii. Canadian Journal of Biochemistry 59, 137-144.

Yoshida, M., Sone, N., Hirata, H. \& Kagawa, Y. (1975). A highly stable adenosine triphosphatase from a thermophilic bacterium. Journal of Biological Chemistry 250, 7910-7916. 